\title{
VARIEDADES
}

\section{EL BAÑO DE BĀB AL-MARDŪM (O DE LA CRUZ): LOCALIZACIÓN E IDENTIFICACIÓN}

\author{
LOCATING AND IDENTIFYING THE BATHS \\ OF BĀB AL-MARDŪN (OR OF THE CROSS)
}

\author{
JEAN PASSINI \\ UMR 8558, CNRS
}

\section{Los datos textuales}

La existencia de al menos un baño en la parroquia de San Nicolás de Toledo (figura 1) viene atestiguada por un pequeño número de documentos notariales de los siglos XII al XV a los que nos vamos a referir a continuación. A fines del siglo XII, concretamente en 1194, Alfonso López vendía en la colación de San Nicolás un baño que había pertenecido a su abuelo, el Conde Pedro Ansúrez ${ }^{1}$. En 1249 el maestre de la orden de Calatrava, Ferrán Ordóñez, donaba al almojarife de Toledo, don Mair, el baño del hospital «cerca de Santa Cruz"2. En 1353 Mencía Sánchez recibía un horno «que es cerca de la iglesia de Santa Cruz que es enfrente del baño que es cerca de la iglesia de Santa Cruz [... $]^{3} \gg$. Un siglo después, en 1460,

${ }^{1}$ Archivo Histórico Nacional (en adelante AHN), Calatrava, Registro I, 138, citado por González, J., Repoblación de Castilla la Nueva, Madrid, 1976, II, 264 y notas 268, 278 y 317.

2 AHN, Calatrava, Registro III, 54, citado por González, Repoblación, II, 264 y nota 280; AHN, Calatrava, 37, en ibidem, I, 118, nota 25; Delgado Valero, C., Toledo islámico: ciudad, arte e historia, Toledo, 1987, 386-387. Véase también Calvo Capilla, S., "La mezquita de Bāb al-Mardūm y el proceso de consagración de pequeñas mezquitas en Toledo (s. XI-XIII)", Al-Qantara, XX (1999), 299-330, nota 15: este baño probablemente fue donado a la Orden de Calatrava en 1194.

3 AHN, San Pedro Mártir, 135: «Mencia Sanchez mujer de Diego Lopez en San Nicolas recibimos un horno que es cerca de la iglesia de Santa Cruz que es enfrente del banno que 


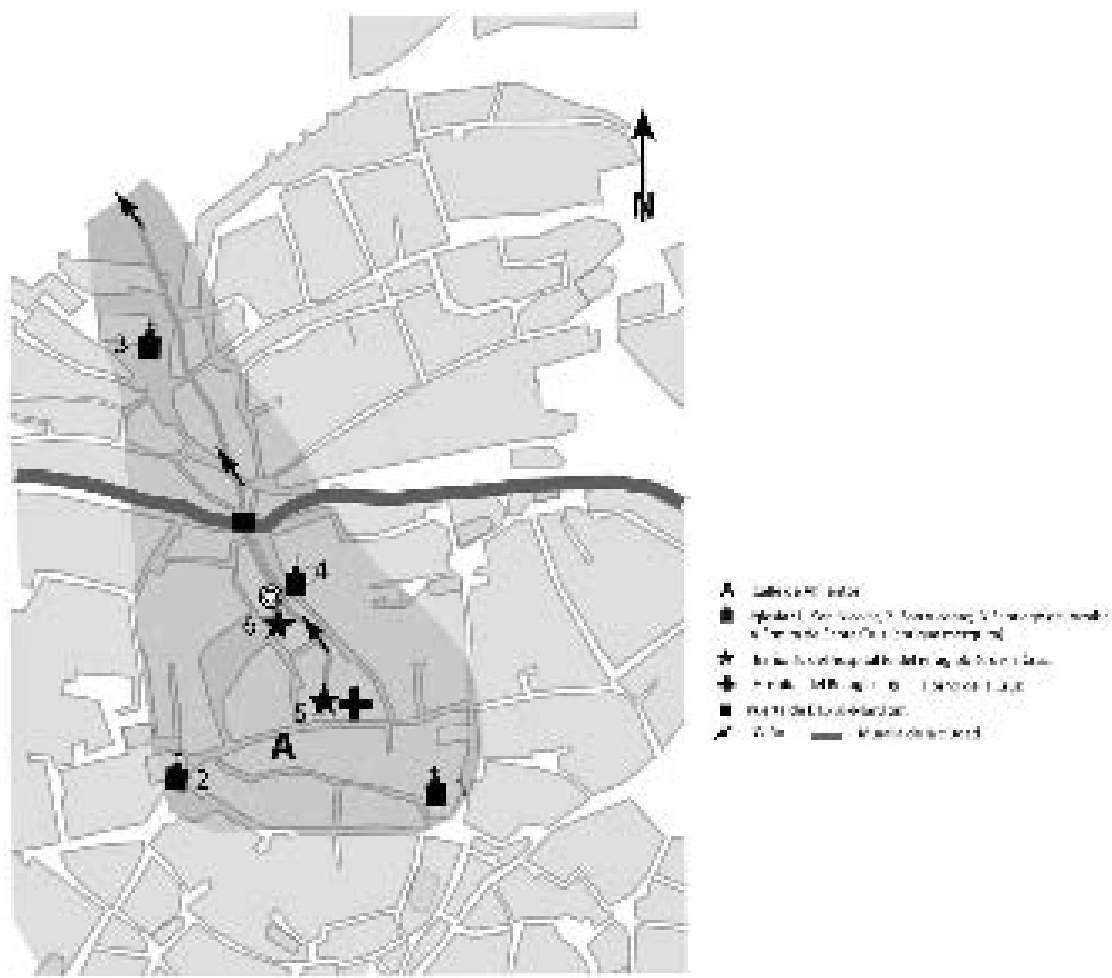

Figura 1. Espacio norte de la colación de San Nicolás.

se explicaba en el inventario de los bienes del monasterio de Santo Domingo el Real que la entrada de una casa de la colación de Santiago del Arrabal daba a "la calle" ${ }_{4}$ o más precisamente, a "el caño" 5 por donde bajaba el agua «de la calle del baño de la Cruz o el agua del baño de la Cruz».

es cerca de esta dicha iglesia [...] se tiene con casas que dicen del almaçerias que son ahora de Suer Gonzalez marques y la otra casa que dice del alfosac (sic) y con la calle [...]».

4 AHN, Clero, Libro 15118, Medidas de casas de Santo Domingo el Real de Toledo (1460), La colación de Santiago del Arraval, casa, fol. 40r-fol. 40v: «Yten otras casas en el dicho arraval en la collacion de la iglesia de Santiago que [...] e tiene mas esta quadra una vara e dos terçias en ancho, la qual manguilla alinda con la calle por do vienen el agua de la calle de vanno de la Crus».

${ }^{5}$ Las aceptaciones de tributo de la casa del arrabal de Santiago al monasterio de Santo Domingo el Real permiten seguir a aquella en 1505, 1511 y 1544: Archivo de 
El «baño de la Cruz», que estaba fuera de uso desde la primera mitad del siglo $\mathrm{XV}^{6}$, se mencionaba todavía a fines del XVI. Un horno de la zona de Santa Cruz aparecía en varios documentos del XVI, alguno de los cuales no llegó a conocer Clara Delgado ${ }^{7}$. En 1517, el monasterio de San Pedro Mártir procedía a medir una casa de la parroquia de San Nicolás «que solia ser horno e se llamaba de la cruz» ${ }^{8}$; el horno de la Cruz era mencionado en una acepta-

Santo Domingo el Real, Becerro, fol. 440r: Santiago, Juana sanches vicaria, «Item tiene el dicho monesterio tresyentos maravedis de çenso e tributo ynphiteosyn en cada un año para siempre Jamas sobre unas casas que son en esta dicha çibdad al arraval en la collaçion de santiago que alindan de la una parte con el caño por donde viene el agua del vaño de la cruz e de la otra parte alinda con casas que fueron de garçia murero e de la otra parte con casas del ospital de sant matheo las quales dichas casas tiene gonçalo ferrandes de sant miguell ortelano vesino de toledo por tresyntos maravedis cada año para siempre jamas pagados por terçios esta posesyon quedo al convento de soror Juana sanches vicaria que dios aya [...] 1505 años. / Las escripturas e titulos que Ay desta posesyon [...] en sabado 16 dias de Agosto de 1511 años mari flores muger del dicho gonçalo ferrandes de sant miguel que dios aya vesina de toledo fiso Reconosçimiento de los dichos tresyentos maravedis del dicho tributo de las dichas casas porque las ella tiene e la pertenesçen que alindan de la una parte con el dicho caño del vaño de la cruz e con casas de la cofradia de sant mateo que tiene a tributo pero muños clerigo e de la otra parte con casas de villafranca cuchillero [...]». Transcripción de Amalia Yuste.

${ }^{6}$ Archivo Municipal de Toledo, Fondo de Cofradías y Hermandades de San Miguel, San Bartolomé y San Pedro, citado en Sánchez Rodríguez, F. y Sánchez Rodríguez, J.L., "Nuevos datos sobre la ubicación de los baños de la cruz y la defensa del patrimonio histórico árabe", en Baños árabes en Toledo, Los monográficos del Consorcio 2, Toledo, 2006, 149157. Se hace referencia al baño de la Cruz en 1425: «[...] unas camaras [...] estavan encima de una bodega [...] e la qual dicha bodega e camara dijo que era del vanno de la Cruz e havia por linderos de la una parte el vaño que dicen de la cruz $[\ldots]$; en $1552,[\ldots]$ casas $[\ldots]$ que han por linderos una parte del vaño que dizen de la Cruz e de las otras partes las calle Real $[\ldots] »$.

7 Delgado Valero, Toledo islámico.

${ }^{8}$ AHN, Clero, leg. 7246, fol. 10 r. y v. «Unas Casas en la dicha perrochia de sant nicolas que solia ser horrno e se llamava de la cruz que agora tyene Alonso Alvarez Ropero con cargo de nueveçientos maravedis de tributo al dicho monesterio de sant pedro martyr que alindan con Casas de alonso herrandes de torres e con calles Reales las quales dichas Casas tyenen las pieças de la medida. Fol. 10v: siguiente un patyo que tyene de largo seys varas e una terçia $\mathrm{E}$ de Ancho quatro varas e media. Un sotano que tyene de largo çinco varas $\mathrm{E}$ dos terçias $\mathrm{E}$ otro tanto en ancho. Un palaçio A mano yzquierda de seys varas en largo e de tres varas E una terçia de ancho. Otro palaçio a mano derecha que tyene de largo seys varas E dos terçias E de ancho tres varas E dos terçias. Un corredor como subimos a mano derecha de siete varas $\mathrm{E}$ media $\mathrm{E}$ otro de la misma manera de la otra parte E de ancho quatro varas E media. Una Camara de seys varas E media en largo E quatro menos dos dedos en ancho. Otra Camara de ocho varas e una ochava de largo e quatro varas menos tres dedos de ancho, esta Camara tyene una chimenea, esta esa posesyon bien Reparada. Una servidunbre de quatro varas menos tres dedos en largo e una vara En ancho. Un sotano que tyene çinco varas e media En quadrado». 
ción de tributo de $1569^{9}$ y $1675^{10}$. En 1728 y 1765 se aludía a cierta casa que estaba en la calle que bajaba a la «ermita de Santa Cruz», al lado de la esquina «del horno de la carcel de la Penitencia $^{11}$, frente al antiguo convento de los Descalzos Agustinos» ${ }^{12}$.

Los textos anteriores nos conducen a las siguientes observaciones:

1. No lejos de la iglesia de Santa Cruz existían estos dos baños en la Edad Media: el baño del hospital (siglo XIII) y un baño que estaba enfrente de un horno (siglo XIV). El nuevo apelativo «de la Cruz», que aparece en el siglo Xv, nos hace suponer que el baño al que se refiere estaba muy cerca de la iglesia de Santa Cruz.

2. La relación de proximidad del «baño del conde Ansúrez», el más antiguo de los conocidos en la colación de San Nicolás, con la iglesia de Santa Cruz, no aparece expuesta en los textos medievales, que tampoco permiten seguir el devenir de este baño.

3. Ninguno de los textos de la Edad Media sitúa los baños con precisión ni proporciona descripción de ellos, aunque no hay duda de que el «de la Cruz», el más cercano a la capilla, estaba en la calle que bajaba de San Nicolás y que la canalización de su agua seguía el trazado de esta calle.

4. Los documentos posteriores al siglo XV confirman la existencia de un horno llamado «de la Cruz» que, probablemente, estaría

9 AHN, Clero, leg. 7239: «Carta de tributo otorgado por Lucas de Pinedo vecino y torres como su fiado de $15.000 \mathrm{mrs}$ [...] Horno de la cruz de coser dicen horno de la cruz, linda arriba con casa de alonso Xerez y dos parte calles reales [...]».

10 Archivo de la Diputación de Toledo (en adelante ADT), Libro, 3186, en 1765: «casa calle que baja a la hermita que hace esquina en la pared mas abajo del Horno de la cruz. Casa a la mano izquierda calle que baja a la ermita que hace esquina en la cera del horno de la carcel de la Penitencia alinda con casa de Jurado Gaspar de Piñedo».

${ }^{11}$ ADT, Libro 3186, en 1517: «Titulos de casa al cristo de la luz comprado en 1728 a maria de Balmeseda en la calle que va al santo cristo de la luz en la esquina de la acera del Horno. [...] linda por dos partes con Francisco de Torres de la otra con casa tributaria al frayles de San Pedro Martir».

${ }_{12}$ AHN, Clero, leg. 7264: «En la calle que va de la iglesia de san Nicolas a la ermita de santa Cruz confronta con el convento antiguo de los descalzos agustinos que hoy sirve de carceles penitenciadas del santo oficio de la inquisition alinde por la parte abajo con casas de juan francisco Sanguinero cavallero de la orden de santiago y de sta crux y por la parte arriba con casa de don thomas hordonez y san pedro cavallero de santiago de la orden y hacen esquina a las dichas casas en la calle del hospital de nuestra señora de la conception en las cuales vive el jurado julian de Pomar[...]».

Al-Qanțara (AQ) XXXI 1, enero-junio 2010, pp. 211-223 ISSN 0211-3589 
muy cerca de la ermita del mismo nombre pero, ¿se trata del mismo horno que se menciona en el siglo XVIII localizado contra el anexo de la cárcel de la Inquisición, haciendo esquina con la calle de la ermita? Intentaremos dar respuesta a esta cuestión, pero antes expondremos los datos obtenidos sobre el terreno.

\section{Los datos materiales}

¿Dónde debemos buscar el baño «de la Cruz»? Tenemos que hacerlo entre las casas de la calle que va de San Nicolás a la ermita del Cristo de la Luz, cerca de una vía de agua que siguiera siendo conocida en el siglo Xv. Creemos probable que esta última coincidía con la vaguada visible desde la calle de Alfileritos a la puerta de Bāb al-Mardūm ${ }^{13}$ (figura 1). Según esta hipótesis, el baño de la Cruz tendría muchas probabilidades de encontrarse en las casas situadas a la izquierda de la calle Cristo de la Luz, muy cerca de la ermita del mismo nombre.

Entre las numerosas casas que hemos visitado, la $\mathrm{n} .{ }^{\circ} 9$ de la cuesta del Cristo de la $\mathrm{Luz}^{14}$ (en la manzana delimitada por esta cuesta, la cuesta de los Carmelitas Descalzos, la calle de los Dos Codos y la travesía de los Dos Codos) ofrece una estructura que evoca un antiguo baño (figura 2). Se trata de un conjunto de tres salas contiguas, situado debajo de la casa principal de la manzana (n. ${ }^{\circ} 1$ de la travesía de los dos Codos).

Se accede a la primera tras franquear un patio porticado y un muro de 1,10 m de grosor. Esta sala, de orientación noroeste-sureste, con bóveda de cañón, mide 9,77 $\mathrm{m}$ en el sentido de la pendiente, $3,20 \mathrm{~m}$ de ancho y $2,40 \mathrm{~m}$ de alto. Incluye en su extremo noroeste una alcoba de 1,02 $\mathrm{m}$ de largo. Muestra en el muro este dos alacenas. La superficie del intradós, que presenta numerosas irregularidades, está perforada por cinco lumbreras distribuidas desigualmente (figura 3).

${ }_{13}$ Passini, J., "Los baños y el agua en Toledo", en Los monográficos del Consorcio 2: Baños árabes en Toledo, Toledo, 2006, 31-46.

${ }_{14}$ Damos las gracias a la propietaria de la planta baja del n. ${ }^{\circ} 9$ de la Cuesta del Cristo de la Luz, que nos facilitó la visita a los sótanos y nos permitió medir y fotografiar las piezas que se mencionan en este artículo. 


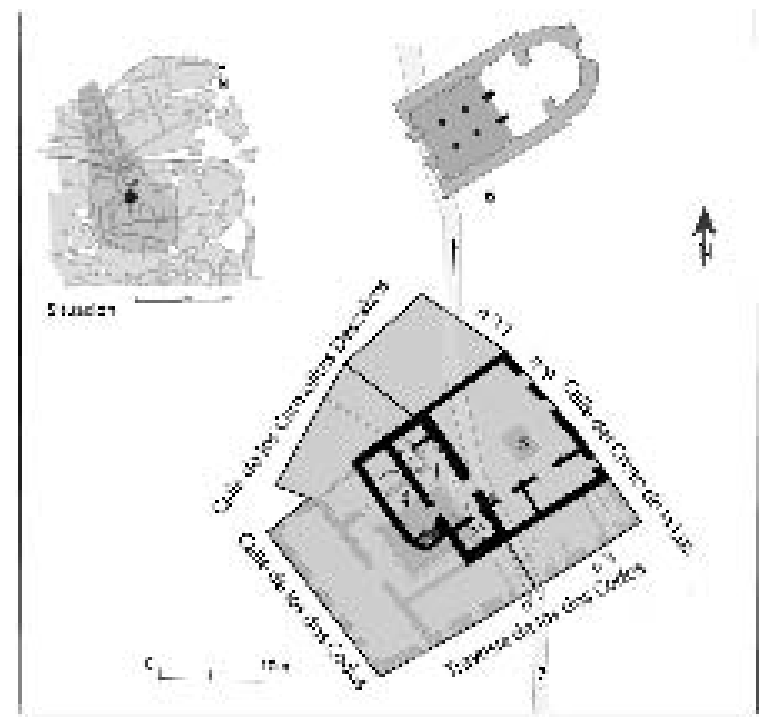

Figura 2. Casa $n .^{\circ} 9$ de la calle del Cristo de la Luz: situación en la manzana y planta baja. 1 y 3. Sala abovedada de dirección NW-SE. 2. Sala abovedada perpendicular. 4. Mina. 5. Patio y portales. 6. Ermita del Cristo de la Luz (Mezquita de Bāb al-Mardūm). 7. Caño (trazado hipotético).

Atravesando un vano del muro, de $0,80 \mathrm{~m}$ de espesor, se llega a una pequeña sala rectangular de $3,20 \times 1,75 \times 2,40 \mathrm{~m}$, cubierta por bóveda de cañón, cuyo eje es perpendicular al de la primera sala (figura 2).

La primera sala comunica por medio de una abertura de $1,07 \mathrm{~m}$ de ancho practicada en un muro de $0,80 \mathrm{~m}$ de espesor con una tercera sala de dirección noroeste sureste, situada bajo la casa principal de la manzana, n. ${ }^{\circ} 1$ de la travesía de los Dos Codos. Esta tercera sala, de 7,94 × 2,58 x 2,12 m, tiene bóveda de cañón cuyo intradós ofrece una superficie regular. En el muro sureste, de 0,40 $\mathrm{m}$ de grosor, una abertura da acceso a un conducto de sección rectangular, de ángulos redondeados, de $0,90 \mathrm{~m}$ de ancho y de $2 \mathrm{~m}$ aproximadamente de largo, al fondo del cual hay una "mina" 15 (figura 4).

15 Recordamos el significado de la palabra "mina": "paso subterráneo abierto con cualquier fin; por ejemplo, para conducir aguas [...]", Moliner, M., Diccionario de uso del español, Madrid, 1984, 417. 


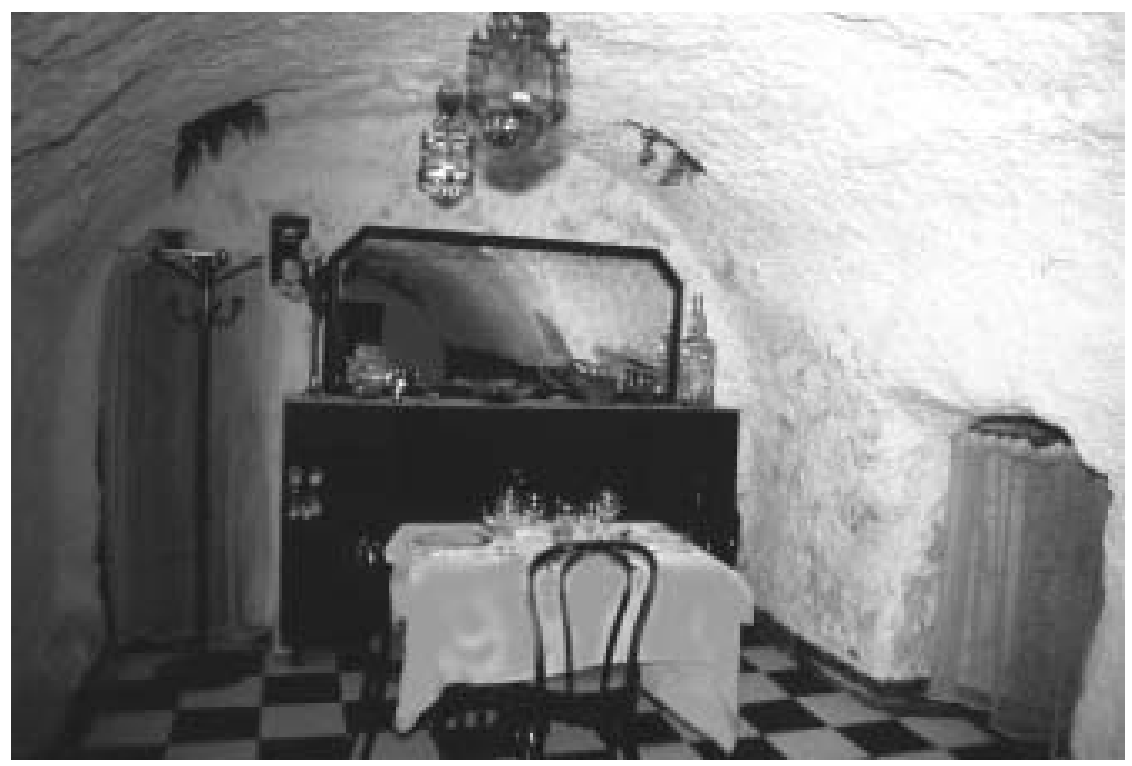

Figura 3. Calle del Cristo de la Luz $n .^{\circ}$ 9: la primera sala con lumbreras.

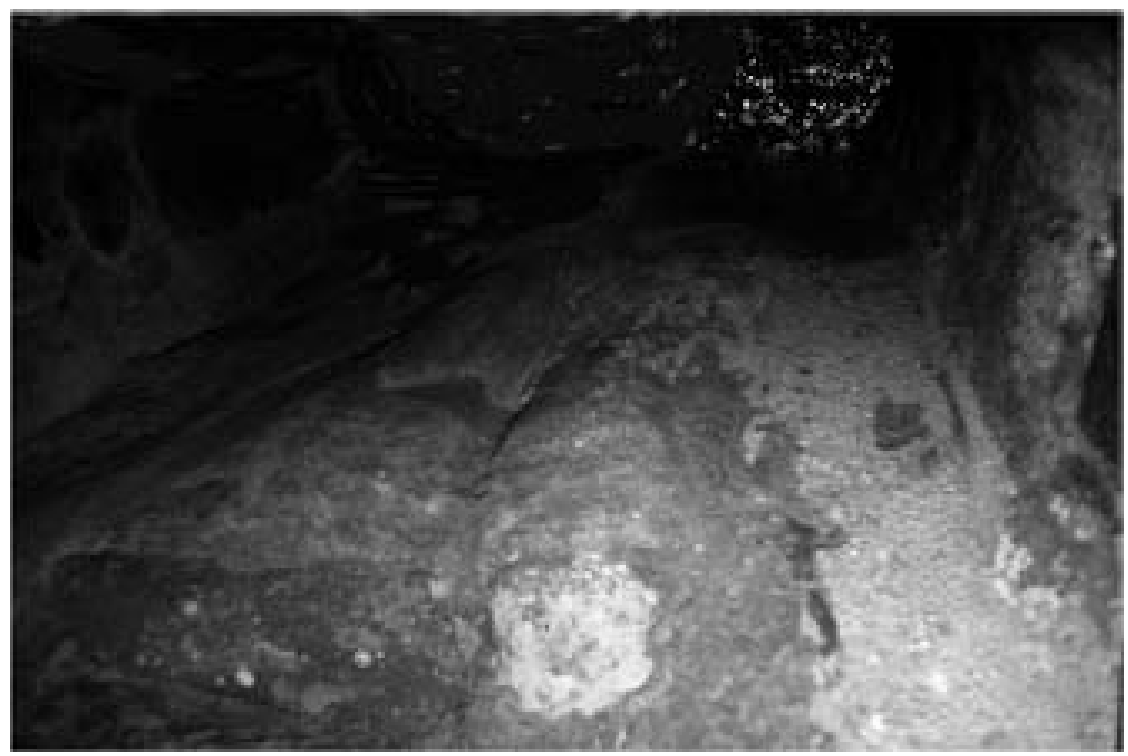

Figura 4. Mina.

Al-Qanțara (AQ) XXXI 1, enero-junio 2010, pp. 211-223 ISSN 0211-3589 
El revoco blanco de los muros de estas tres salas impide cualquier observación del aparejo de los muros y de las bóvedas. Sin embargo, el paramento exterior que prolonga el muro sureste de la segunda sala, se puede ver desde dentro del sótano del $\mathrm{n}^{\circ} 3$ de la travesía de los Dos $\operatorname{Codos}^{16}$ (figura 5) y muestra una alternancia de robustos mampuestos rematados por una o dos hiladas de ladrillos de 0,28 a $0,30 \mathrm{~m}$ de grosor (figura 5).
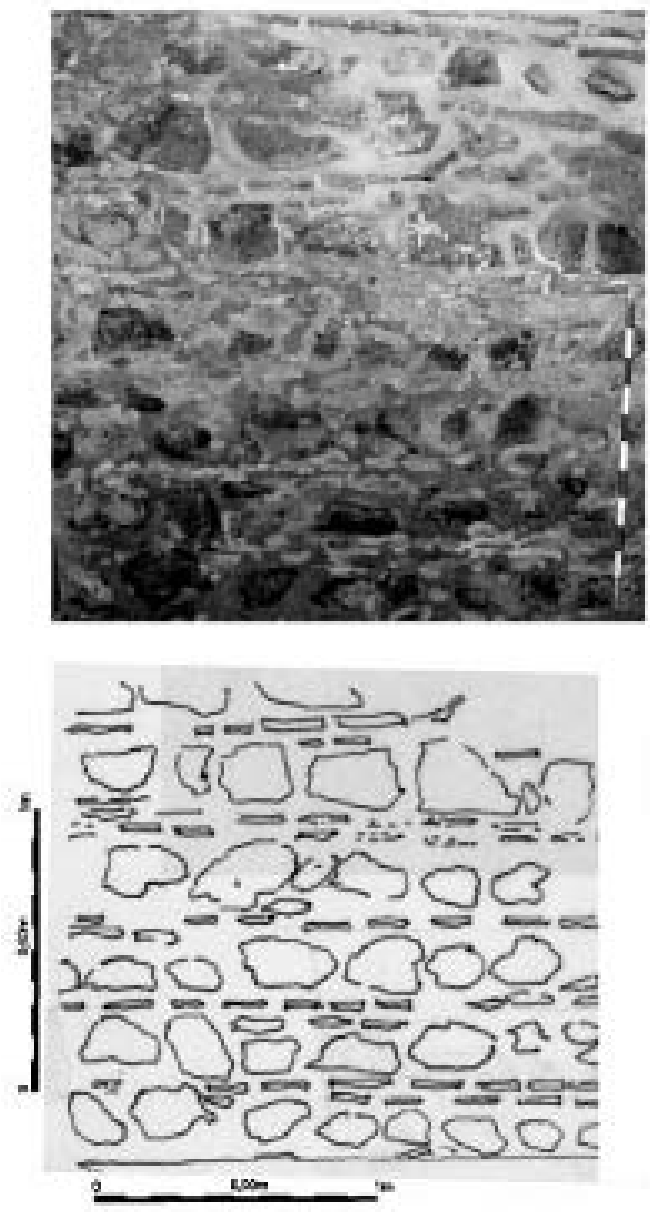

Figura 5. Aparejo del muro exterior prolongación de la sala 2.

16 Agradecemos su acogida a Antonio Martínez.

Al-Qanțara (AQ) XXXI 1, enero-junio 2010, pp. 211-223 ISSN 0211-3589 
Este conjunto de tres salas rectangulares cubiertas con bóveda de cañón, hallado en la manzana de la Cuesta de la Cruz ceñida por la calle y la travesía de los Dos Codos, se manifiesta claramente como los restos de un baño islámico.

\section{Interpretación: intento de restitución del baño.}

La presencia constante de agua en el subsuelo de esta manzana, referida en algunos documentos de archivo de los siglos XV y XVI a causa de la existencia de un «caño del baño de la cruz», visible en la actualidad a nivel de la «mina» y de un pozo en el patio del este, hacía que este lugar, muy cercano además a la antigua mezquita de la Cruz, fuera idóneo para la construcción de un baño.

El baño sólo es visible desde una parte de la manzana. Teniendo en cuenta que dos de las tres salas conservadas se sitúan bajo la que hoy día es la casa principal de la manzana, en el n. ${ }^{\circ} 1$ de la travesía de los Dos Codos, podemos plantearnos si la edificación de esta casa en la segunda mitad del siglo $\mathrm{XV}^{17}$ no acarreó la destrucción del edificio antiguo, lo que conllevaría la desaparición de parte de los elementos que componían el baño. Esta hipótesis justifica la restitución que presentamos aquí (figura 6). Proponemos atribuir a la sala que está más al este, cuyo muro exterior es el más grueso, la función de sala caliente (al-bayt al-sajūn). Se comunicaba con la sala templada (al-bayt al-wastânnī) y además con una sala de paso. De esta última sólo se conserva una parte. La sala fría, que se comunicaba con la templada, debía de estar más al oeste.

En cuanto a la caldera, que se situaba habitualmente más abajo de la sala caliente a fin de calentar el hipocausto, debía de estar, teniendo en cuenta la fuerte pendiente del suelo en sentido oeste-este, al este del conjunto descrito, concretamente en el sitio del actual patio de la casa n. ${ }^{\circ}$ 9. El baño de la Cruz muestra en las partes actualmente visibles las características ya conocidas de los baños islámicos de Toledo. La superficie de las salas caliente y templada, de 31,26 y $20,48 \mathrm{~m}^{2}$ respectivamente, es semejante a la de las salas caliente, $29,74 \mathrm{~m}^{2}$, y templada, $24,41 \mathrm{~m}^{2}$, del baño de San Sebastián

17 Datación establecida basándonos en la decoración que se observa en la casa.

Al-Qanțara (AQ) XXXI 1, enero-junio 2010, pp. 211-223 ISSN 0211-3589 


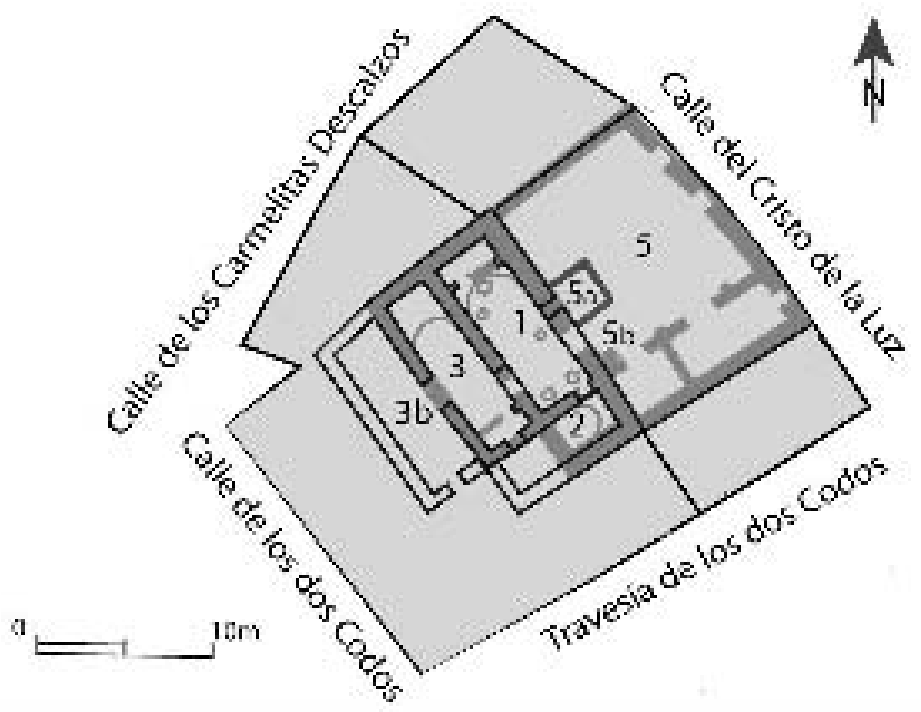

תuro restituido

muro hipotcitiso

nuro existents

Figura 6. Baño de la Cruz en el siglo XI: restitución.

1. Sala caliente, 2. Sala de paso, 3. Sala templada, 3b. Sala fría, 5a. Caldera, 5b. Pozo.

de Yuso ${ }^{18}$. Añadamos que el grosor de los muros interiores $(0,80 \mathrm{~m})$ y el aparejo exterior de la prolongación del muro sur de la sala de paso muestran características de las construcciones islámicas toledanas, como puede verse en los baños de San Sebastián de Yuso, de Suso ${ }^{19}$ y del Pozo Amargo ${ }^{20}$.

¿Qué relación unía a este baño islámico con la vecina mezquita de Bāb al-Mardūm, de la que sólo lo separa una veintena de metros? (figura 7). Antes de responder a esta cuestión, una breve pun-

18 Passini, J., Rojas Rodríguez-Malo, J.M. y Ramón Villa, J., "Los baños extramuros de San Sebastián", Al-Qanțara, XVIII, 1 (1997), 187-219.

19 Ibid. $35-46$

${ }^{20}$ Passini, J., "Le bain du Pozo Amargo (Tolède)", Archéologie islamique, 5 (1995),

Al-Qanțara (AQ) XXXI 1, enero-junio 2010, pp. 211-223 ISSN 0211-3589 


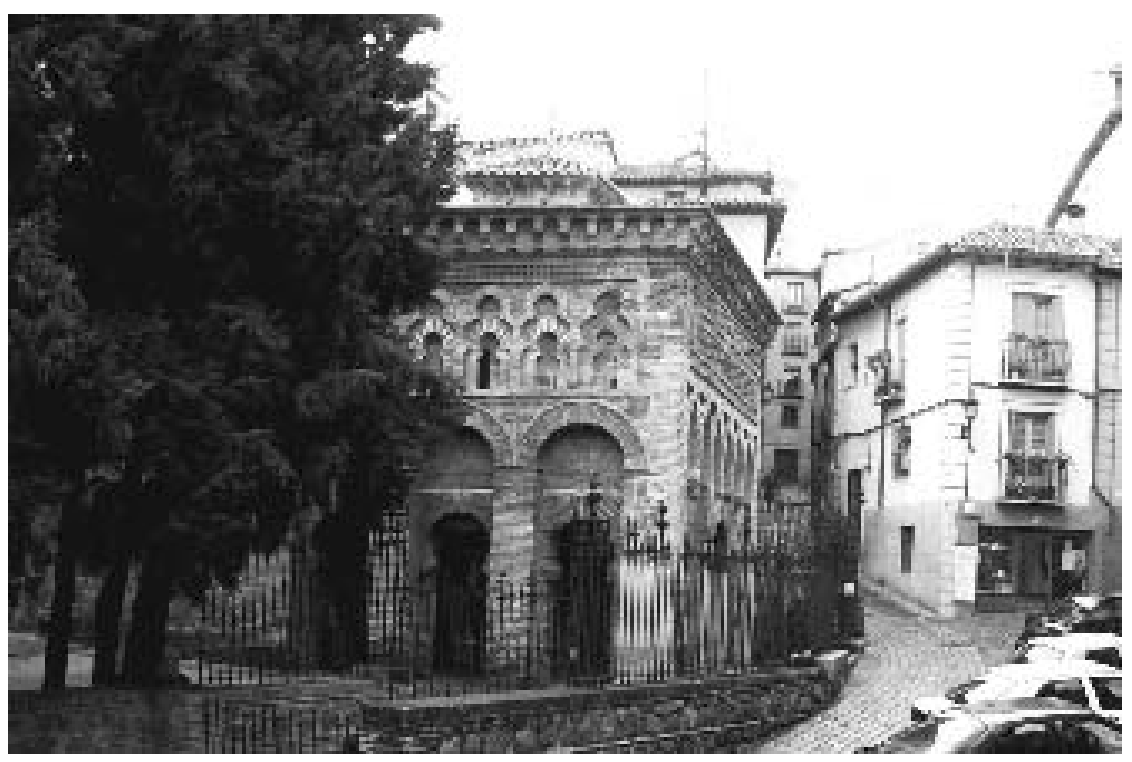

Figura 7. Ermita del Cristo de la Luz y manzana donde se encuentran las estructuras del baño.

tualización histórica: la pequeña mezquita de Bāb al-Mardūm, financiada por un miembro de una gran familia toledana, Ibn al-Hadīīī, se edificó en el año $999^{21}$ cerca de la puerta del mismo nombre ${ }^{22}$. Llevó sin duda durante el siglo XI el nombre de su fundador antes de convertirse, un siglo más tarde, simplemente en «unam casam que diciture de Sancta Cruce, que olim fuit mesquita maurorum», cuyos dueños la cedieron en 1183 a la Orden de San Juan de Jerusalén ${ }^{23}$. Desconocemos los motivos que tuvo el fundador para elegir ese emplazamiento para la pequeña mezquita. ¿Existía ya un baño en las cercanías, o quizás ese baño fue encargado también por el generoso fundador? Según la respuesta que conven-

${ }^{21}$ Ewert, C., "La mezquita de Bāb al-Mardūm de Toledo (Cristo de la Luz): una copia de la mezquita de Córdoba", en Entre el Califato y la Taifa: Mil años del Cristo de la Luz. Actas del Congreso Internacional (1999), Toledo, 2000, 11-52.

${ }^{22}$ Calvo Capilla, S., "Reflexiones sobre la mezquita de Bāb al-Mardūm y la Capilla de Belén (Convento de Santa Fe) de Toledo a la luz de nuevos datos", en Entre el Califato y la Taifa, Toledo, 2000, 335-41; idem, "La mezquita de Bāb al-Mardūm", 299-330.

${ }^{23}$ Ibid.

Al-Qanțara (AQ) XXXI 1, enero-junio 2010, pp. 211-223 ISSN 0211-3589 
ga a esta cuestión, el baño descrito más arriba habría sido edificado en el siglo $\mathrm{x}$, quizás incluso antes, o bien a principios del XI. De cualquier manera, el baño de Bāb al-Mardūm debió de ser utilizado por los que frecuentaban la pequeña mezquita. Puede que a ambas construcciones les cupiera, inmediatamente después de la reconquista, una suerte algo mejor que la de los otros baños. Quizás fue donado a algún rico personaje cercano, por ejemplo, al Conde Pedro Ansúrez ${ }^{24}$, del que sabemos era familiar del rey Alfonso VI ${ }^{25}$. Vendido en 1194, en lo sucesivo se lo conocería únicamente con la expresión «baño de la Cruz».

En conclusión, la mezquita y el baño de Bāb al-Mardūm formaban, cerca de la puerta principal de Toledo, un conjunto pleno de significado para los viajeros que lo percibían de golpe cuando franqueaban la puerta de Bāb al-Mardūm (figura 8). El baño subrayaba el lugar donde la vía principal se dividía en dos calles importantes, una hacia el zoco y los mesones del Hierro, del Carbón y de las Muelas, y la otra hacia el barrio de San Román. Este conjunto, de una pequeña mezquita y baño que volvemos a encontrar en las medinas de Marrakech o de Fez, caracterizaba las ciudades arabo-musulmanas medievales.

Recibido: $17 / 11 / 2007$

Aceptado: 24/06/2009

${ }^{24}$ El baño vendido en 1194 (vid supra) había pertenecido al Conde Pedro Ansúrez.

${ }_{25}$ El Conde Pedro Ansúrez acompañó a Alfonso VI en la provincia de Toledo en 1072, antes de la conquista de la ciudad. Véase González, Repoblación de Castilla la Nueva, I, 118 y nota 24.

Al-Qanțara (AQ) XXXI 1, enero-junio 2010, pp. 211-223 ISSN 0211-3589 


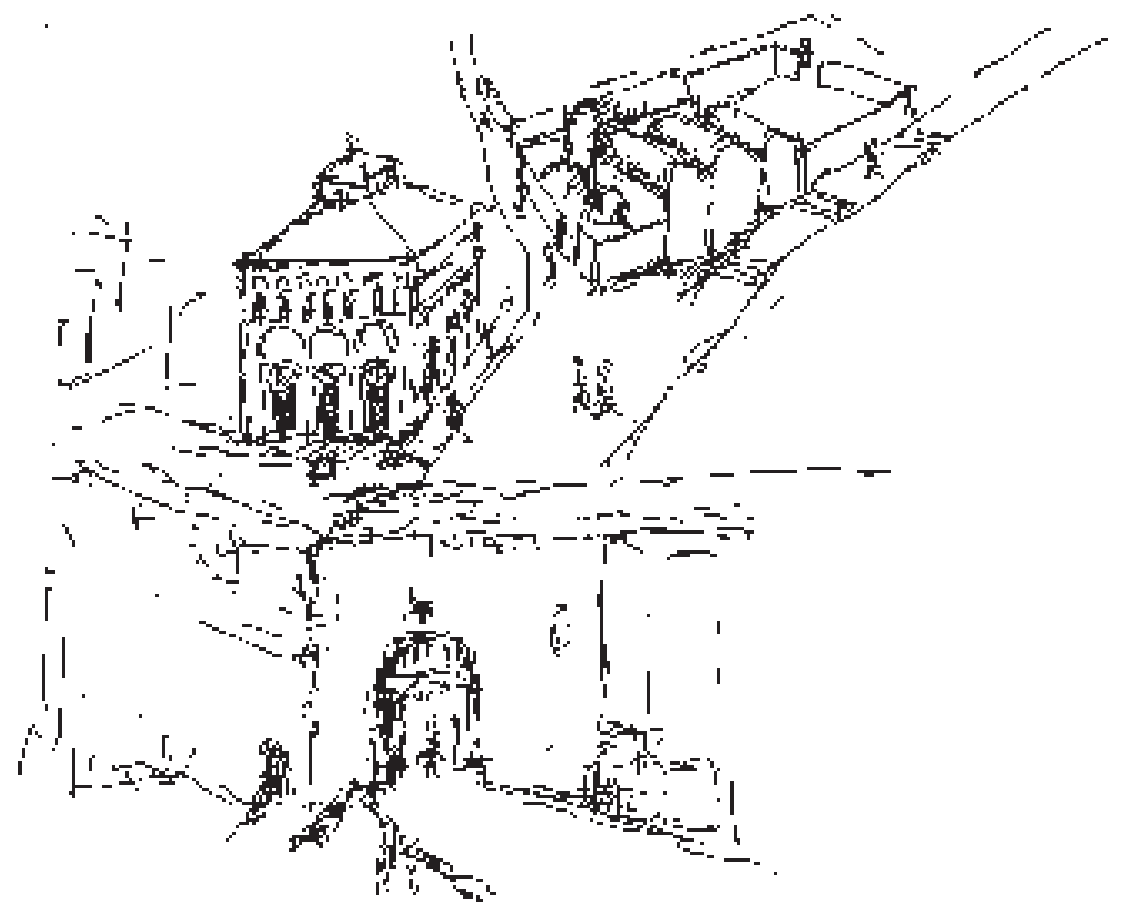

Figura 8. Vista desde la puerta de Bab al-Mardum a principios del s. XI: la pequeña mezquita de Ibn al-Hadīdī y el baño adyacente. 